\title{
Deep time course proteomics of SARS-CoV- and SARS-CoV-2-infected human lung epithelial cells (Calu-3) reveals strong induction of interferon-stimulated gene (ISG) expression by SARS-CoV-2 in contrast to SARS-CoV
}

\author{
Authors \\ Marica Grossegesse ${ }^{1}$, Daniel Bourquain ${ }^{2}$, Markus Neumann ${ }^{1}$, Lars Schaade ${ }^{2}$, Jessica \\ Schulze ${ }^{4}$, Christin Mache ${ }^{4}$, Thorsten Wolff ${ }^{4}$ Andreas Nitsche ${ }^{1}$ and Joerg \\ Doellinger ${ }^{1,3 *}$

\section{Affiliations} \\ ${ }^{1}$ Robert Koch Institute, Centre for Biological Threats and Special Pathogens: Highly \\ Pathogenic Viruses (ZBS 1) \\ ${ }^{2}$ Robert Koch Institute, Centre for Biological Threats and Special Pathogens \\ ${ }^{3}$ Robert Koch Institute, Centre for Biological Threats and Special Pathogens: \\ Proteomics and Spectroscopy (ZBS 6) \\ ${ }^{4}$ Robert Koch Institute, Unit 17, Influenza and Other Respiratory Viruses \\ *corresponding author(s): Joerg Doellinger (Doellingerj@,rki.de)
}

\section{Supporting Information}




\section{TABLE OF CONTENTS}

1. Supporting tables (.xlsx file)

SI Table 1: DIA Windows

SI Table 2: Viral protein expression (mean log2 values)

SI Table 3: Human proteins affected by infection (log2 transformed)

SI Table 4: ClueGO Result Human Cluster 1

SI Table 5: ClueGO Result Human Cluster 2

SI Table 6: ClueGO Result Human Cluster 3

SI Table 7: STRING enrichment (biological process)

SI Table 8: STRING enrichment (molecular function)

SI Table 9: STRING enrichment (cellular compartment)

SI Table 10: Protein output table

SI Table 11: Global proteome expression studies of SARS-CoV-2 infected human cell lines

2. Supporting figures

SI Figure 1: Cytopathic effect and IRF activity 
A

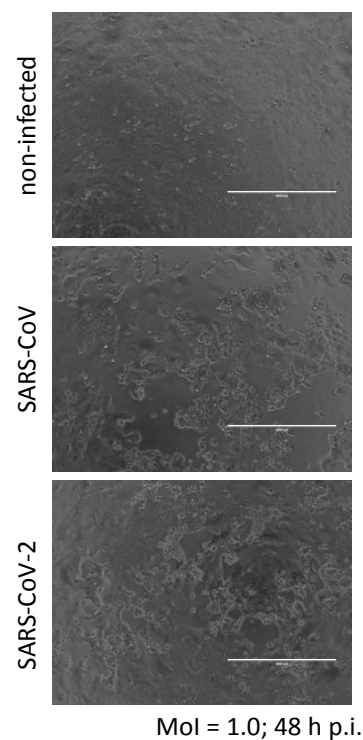

B

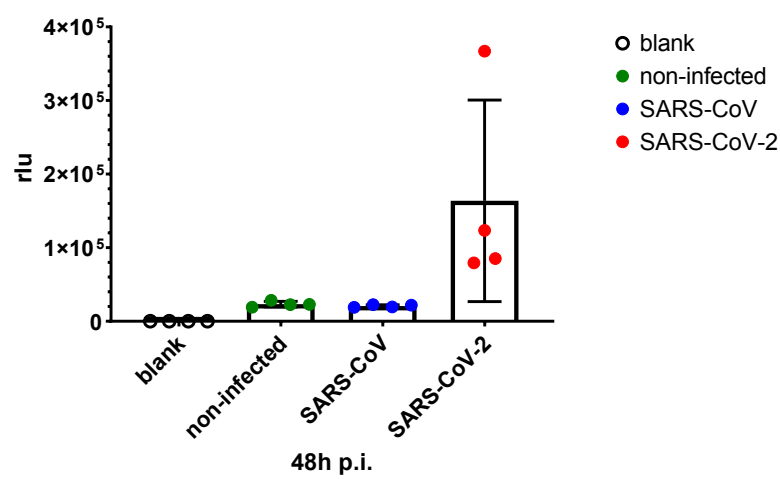

SI Figure 1. (A) Cytopathic effect and (B) IRF activity $48 \mathrm{~h}$ post SARS-CoV and SARS-CoV-2 infection of A549-Dual-ACE2 cells $(\mathrm{MOI}=1)$. 